\title{
The Effects of Alkalinity and Hypertonicity on the Morphology and Motility of Leptospira interrogans (biflexa) strain B16
}

\author{
By G. E. KAISER AND R. N. DOETSCH \\ Department of Microbiology, University of Maryland, Maryland 20705, U.S.A.
}

(Received 20 October 1975)

\begin{abstract}
SUMMARY
Effects of alkalinity and hypertonicity on the motile behaviour of Leptospira interrogans (biflexa) BI 6 were observed, quantified, and compared with effects previously shown by similar factors on the motility of eubacteria. Leptospira interrogans tolerated relatively high concentrations of hydroxide ions. Motility similar to that in controls was observed at $\mathrm{pH}$ values up to 9.8 ; but at $\mathrm{pH} 10.0$ motility declined sharply with time of exposure, and there was structural alteration, visible as a blebbing of the cell envelope. Unlike the behaviour of eubacteria, immobilization of $L$. interrogans induced by hydroxide ions could not be reversed by lowering the $\mathrm{pH}$. It is suggested that by restricting entry of hydroxide ions, the cell envelope protects its motility apparatus from adverse effects.

Leptospira interrogans was completely immobilized in $0.5 \mathrm{M}$ and $\mathrm{I} \cdot 0 \mathrm{M}$-sucrose solutions. Unlike the eubacteria, leptospires were incapable of spontaneous reversion to motile forms and resumption of motility was dependent on both concentration and time of exposure to sucrose. Deuterium oxide did not affect movement, suggesting that even though leptospire endoflagella and the exoflagella of eubacteria are analogous, the motile behaviour of $L$. interrogans is significantly different from that of eubacteria.
\end{abstract}

\section{INTRODUCTION}

Although the motion of leptospires has fascinated bacteriologists for decades, little is known about their motility and how it is affected by environmental factors. Furthermore, descriptions of leptospiral motility are generally subjective and qualitative rather than quantitative.

Kaiser \& Doetsch (1975) showed that translational movement of Leptospira interrogans (biflexa) в 6 was enhanced in viscous solutions. In $\mathrm{SM}_{4}$ medium supplemented with methyl cellulose, there was a marked increase both in the number of individual organisms exhibiting translational movement and in the velocity they attained, with maxima at viscosities exceeding $300 \mathrm{cP}$. The motile behaviour observed in such very viscous solutions contrasts markedly with that of flagellated bacteria, which show an increase in velocity as viscosity is elevated to 2 to $5 \mathrm{cP}$ (depending on the organism and its flagellar arrangement), but then a rapid decrease in velocity at higher viscosities (Schneider \& Doetsch, 1974). Thus environmental viscosity affects the motility of leptospires differently from that of flagellated bacteria.

Two other environmental factors known to influence the motility of eubacteria are $\mathrm{pH}$ and hypertonicity. Alkaline $\mathrm{pH}$, in the range $9 \cdot 4$ to $10 \cdot 0$, causes immobilization of various Gram-negative bacteria, presumably by paralysing their flagella-activating system (Schuetze \& Doetsch, 1967). Reversal of paralysis may readily be accomplished by lowering the $\mathrm{pH}$. Plasmolysis of eubacteria with either sucrose solutions (Okrend \& Doetsch, 1969) 
or ${ }^{2} \mathrm{H}_{2} \mathrm{O}$ (Zipf \& Doetsch, I973) also reversibly inhibits bacterial motility, probably by causing a disruption between the cytoplasmic membrane and flagella. Resumption of motility occurs either spontaneously with time or on deplasmolysis (Okrend \& Doetsch, I969).

We describe attempts to quantify the effects of alkalinity and hypertonicity on leptospiral motility, and to compare them with those observed with eubacteria.

\section{METHODS}

Culture maintenance. Leptospira interrogans (biflexa) strain ві6, used throughout this study, was graciously provided by Dr C. D. Cox, University of Massachusetts, Amherst, Massachusetts, U.S.A. Strain BI6 is a freshwater isolate capable of excellent growth in synthetic media (Henneberry, Baseman \& Cox, 1970) and was chosen for study because it is easy to maintain, avirulent, and does not require animal serum. For motility experiments, screw-capped culture tubes containing Io $\mathrm{ml} \mathrm{SM}_{4}$ medium (Henneberry et al., 1970) were inoculated with $0.5 \mathrm{ml}$ stock culture and incubated in a temperature-controlled oscillating shaker at $30^{\circ} \mathrm{C}$ for 48 or $72 \mathrm{~h}$. Leptospires had optimum motility during this time.

Preparation of alkaline test solutions. 3-(Cyclohexylamino) propane sulphonic acid (CAPS; Polysciences, Warrington, Pennsylvania, U.S.A.; $\mathrm{p} K_{\mathrm{a}} \mathrm{IO} \cdot 4$ at $20{ }^{\circ} \mathrm{C}$ ) was required at $7.5 \times 10^{-3} \mathrm{M}$ to maintain a stable alkaline $\mathrm{pH}$ throughout the experiment, without adversely affecting the motion or growth of $L$. interrogans. Immediately before use, $100 \mathrm{ml}$ quantities of the buffer were adjusted to various $\mathrm{pH}$ values between $7 \cdot 3$ and I $\cdot 0$ using I M$\mathrm{NaOH}, \mathrm{NH}_{4} \mathrm{OH}$ or $\mathrm{KOH}$. $\mathrm{pH}$ measurements were made with a Radiometer $\mathrm{pH}$ meter model 28 (Radiometer Corp., Copenhagen, Denmark).

In experiments with EDTA, $5 \times 10^{-3} \mathrm{M}$-disodium EDTA was prepared in $100 \mathrm{ml} 7.5 \times 10^{-3}$ $\mathrm{M}$-CAPS buffer and the final $\mathrm{pH}$ was adjusted to $7 \cdot 3$ or $9 \cdot 6$ with I $\mathrm{M}-\mathrm{NaOH}$.

Preparation of alkaline suspensions. Millipore Swinnex-25 filter holders (SX HA 02505) were modified so that $10 \mathrm{ml}$ syringes could be coupled at each end, and used to force fluids in either direction through the holder without rupturing the filter. Using these, the organism could be separated from its growth medium, washed, and resuspended in test solution without centrifuging (which might have caused structural damage to the leptospiral cell envelope and thereby a change in motility). Repeated filtering, washing and resuspension did not affect leptospiral morphology or motion.

Samples ( $2 \mathrm{ml}$ ) of a $48 \mathrm{~h}$ culture of $L$. interrogans were pipetted into the barrel of a $10 \mathrm{ml}$ syringe coupled to a modified Swinnex-25 filter holder,'containing a $25 \mathrm{~mm}$ diam. Millipore filter, pore size $0.45 \mu \mathrm{m}$. The growth medium was gently forced through the filter so that the leptospires collected on the filter surface. The filter holder was then inverted, another syringe barrel was inserted (on the opposite side to the first one), and $4 \mathrm{ml}$ test solution was forced through the filter to resuspend the organisms which were collected in a clean culture tube. This served as a wash step. The washed suspension was passed in the same manner through a second filter, and the leptospires were again resuspended in the test solution.

Motility studies. Leptospiral test suspension (Io $\mu \mathrm{l}$ ) was placed on a $75 \times 25 \mathrm{~mm}$ glass slide, and covered with a $22 \times 22 \mathrm{~mm}$ coverslip ( 0.19 to $0.25 \mathrm{~mm}$ thick), sealed at its edges with petroleum jelly to prevent currents and 'drifting'. The slide was examined immediately under dark-field illumination using a Zeiss Photomicroscope I equipped with a $40 \times$ oilimmersion apochromatic objective. Approximately 200 organisms were counted at random locations and the ratio of motile organisms, i.e. those having either translational or nontranslational motion, to total organisms was determined. The first determination was made 
immediately after the organism had been suspended in the test solution and subsequent determinations were carried out after 5, I0, I5, 30 and $60 \mathrm{~min}$. Tests were performed in triplicate.

Hypertonicity studies. Sucrose was dissolved in $100 \mathrm{ml} \mathrm{I0}^{-3} \mathrm{M}-3-(N$-morpholino $)$ propane sulphonic acid (MOPS; Polysciences) to give a final concentration of $0.5 \mathrm{M}$ or $\mathrm{I} \cdot 0 \mathrm{M}$, and the final $\mathrm{pH}$ was adjusted to $7 \cdot 3$ with I $\mathrm{M}-\mathrm{NaOH}$. Bacteria from $2 \mathrm{ml}$ of culture were washed and resuspended in these sucrose solutions and ro $\mu \mathrm{l}$ portions were examined at intervals to determine the percentage of motile organisms.

For recovery experiments, the leptospires were exposed to $0.5 \mathrm{M}$ or $\mathrm{I} \cdot 0 \mathrm{M}$-sucrose for $5,15,30$ or $60 \mathrm{~min}$, after which, the sucrose was removed and the organisms were washed and resuspended in $4.0 \mathrm{ml}$ of $\mathrm{IO}^{-3} \mathrm{M}$-MOPS buffer or SM4 medium. Samples were again examined at intervals to determine the percentage of organisms recovering. Neither the motility nor the morphology of the organism was affected by washing twice with $10^{-3} \mathrm{M}$ MOPS buffer.

For studies of the effect of suspension in deuterium oxide, bacteria from $0.5 \mathrm{ml}$ of culture were washed and resuspended in $2.0 \mathrm{ml} 99.8 \%(\mathrm{v} / \mathrm{v}){ }^{2} \mathrm{H}_{2} \mathrm{O}(\mathrm{pH} 6 \cdot 5)$. Samples were examined microscopically at intervals for up to $2 \mathrm{~h}$ and the percentage of organisms retaining motility was determined.

Dark-field photography. Photographs were taken using a Zeiss Photomicroscope II equipped with a Zeiss microflash device and a Ukatron UN-60 microflash generator. A 60 Ws discharge was used, except for time exposures, which used a $6 \mathrm{~V}$ focusing light and four separate $30 \mathrm{Ws}$ discharges fired manually at $5 \mathrm{~s}$ intervals. Dark-field illumination was used with a $40 \times$ or $100 \times$ oil-immersion apochromatic objective, a $3.2 \times$ projective, and a $\mathrm{I} \cdot 25, \mathrm{I} \cdot 6$ or $2 \cdot 0 \times$ optovar. Kodak Tri-X Pan film, ASA 400 , was used.

\section{RESULTS}

\section{Effect of alkalinity on leptospiral motion}

When leptospires were washed and resuspended in $7.5 \times 10^{-3} \mathrm{M}-\mathrm{CAPS}$ buffer, adjusted to various $\mathrm{pH}$ values with I $\mathrm{M}-\mathrm{NaOH}$, their motion was affected as shown in Table I. Even with exposures of up to $\mathrm{I} h$ at $\mathrm{pH} 9 \cdot 8$, over $90 \%$ of the organisms showed some form of translational or non-translational motion. When the $\mathrm{pH}$ was raised to 10.0, however, the percentage of leptospires showing movement declined drastically with time, ranging from $90 \%$ motility after $5 \mathrm{~min}$ to only $7 \%$ motility after $\mathrm{I} \mathrm{h}$. At $\mathrm{pH}$ 10.6, all motion stopped within the first $5 \mathrm{~min}$ of exposure.

At $\mathrm{pH} 9.6$ the leptospires appeared morphologically normal (Fig. $\mathrm{I} a$ ); but at $\mathrm{pH}$ I0.0 structural alterations were seen in conjunction with the cessation of motility. After to to I 5 min in a $\mathrm{pH}$ 10.0 solution, small blebs developed at one end of the organism (Fig. I $b$ ). After a longer exposure time, more organisms were observed to have blebs, many of which were larger in diameter (Fig. I c). In organisms possessing large blebs, the intact 'nonblebbed' portion was significantly shorter than in organisms with only small blebs. After I h a number of spherical membrane-like particles or spherules were evident (Fig. I $d$ ). Organisms with visible structural changes were seldom motile, but non-motile cells with no visible alteration in appearance also were observed.

At $\mathrm{pH} 10 \cdot 6$, all organisms ceased to move within the first $5 \mathrm{~min}$ of exposure and almost every one either possessed a bleb or was in a spherule form. Once most of the organisms either began forming blebs or stopped moving, the process could not be reversed by lowering the $\mathrm{pH}$. Motility inhibition and structural damage as a result of alkalinity thus appear to 


\title{
Table I. Effect of alkalinity on leptospiral motion
}

\begin{abstract}
Leptospires were suspended in $7.5 \times 1 \mathrm{IO}^{-3} \mathrm{M}$-CAPS buffer, adjusted to the final $\mathrm{pH}$ given by addition of I $\mathrm{M}-\mathrm{NaOH}$. Motility is expressed as the percentage of leptospires showing either translational or non-translational motion of any kind. Each test was performed in triplicate, and the range of results is given in parenthesis.
\end{abstract}

$\begin{array}{ccc}\text { Final pH } & \text { Exposure time (min) } & \text { Average motility (\%) } \\ 7.3 & 5 & 95(93-97) \\ & 10 & 96(95-97) \\ & 15 & 95(92-97) \\ 9 \cdot 6 & 30 & 93(92-94) \\ & 60 & 94(93-96) \\ & 5 & 95(94-96) \\ & 10 & 93(92-95) \\ 9 \cdot 8 & 15 & 93(92-94) \\ & 30 & 93(92-94) \\ & 60 & 94(93-95) \\ & 5 & 97(96-97) \\ 10 \cdot 0 & 10 & 96(95-97) \\ & 15 & 96(95-97) \\ & 30 & 96(95-97) \\ & 60 & 97(96-98) \\ 10.6 & 5 & 90(84-92) \\ & 10 & 74(65-86) \\ & 15 & 50(45-55) \\ & 30 & 25(19-29) \\ & 60 & 7(5-8) \\ & 5 & 0 \\ & 10 & 0 \\ & 15 & 0 \\ & 30 & 0 \\ 60 & 0\end{array}$

be permanent. If the $\mathrm{pH}$ was increased to I $\cdot 0$, all cells immediately lysed and assumed a 'moth-eaten' appearance (Fig. I $e$ ).

It seems likely that the small blebs begin as a pulling away of the envelope from the protoplasmic cylinder at one end of the organism. This process continues down the entire length (hence the shortened appearance of cells with large blebs) until the organism assumes a spherical form, presumably with the protoplasmic cylinder folded up on itself within the bounding membrane. Similar changes have been reported in leptospires exposed to other adverse conditions (Auran, Johnson \& Ritzi, I972; Kiktenko, Bakulina \& Levina, 1974).

To determine whether $\mathrm{Na}^{+}$ions specifically affected leptospiral motion, the same experimental procedures were carried out using $\mathrm{KOH}$ or $\mathrm{NH}_{4} \mathrm{OH}$ instead of $\mathrm{NaOH}$. The results are summarized in Fig. 2.

It seemed possible that the leptospiral membrane might play a role in the resistance to hydroxide ions. EDTA chelates $\mathrm{Mg}^{2+}$ from biological membranes and causes either a breakdown of the membrane or an alteration in its permeability (Indge, 1968). The experiments described above were therefore repeated in the presence of $5 \times 10^{-3} \mathrm{M}$-disodium EDTA (Fig. 3). At pH 7.3, EDTA did not affect leptospiral motion. The results observed at $\mathrm{pH} 9.6$ in the presence of EDTA, however, are strikingly different from those obtained in the absence of EDTA. In addition, blebs and spherules, such as those normally observed at $\mathrm{pH}$ I0.0 to 10.6 , were frequently seen at $\mathrm{pH} 9.6$ when EDTA was present in the suspending medium. 

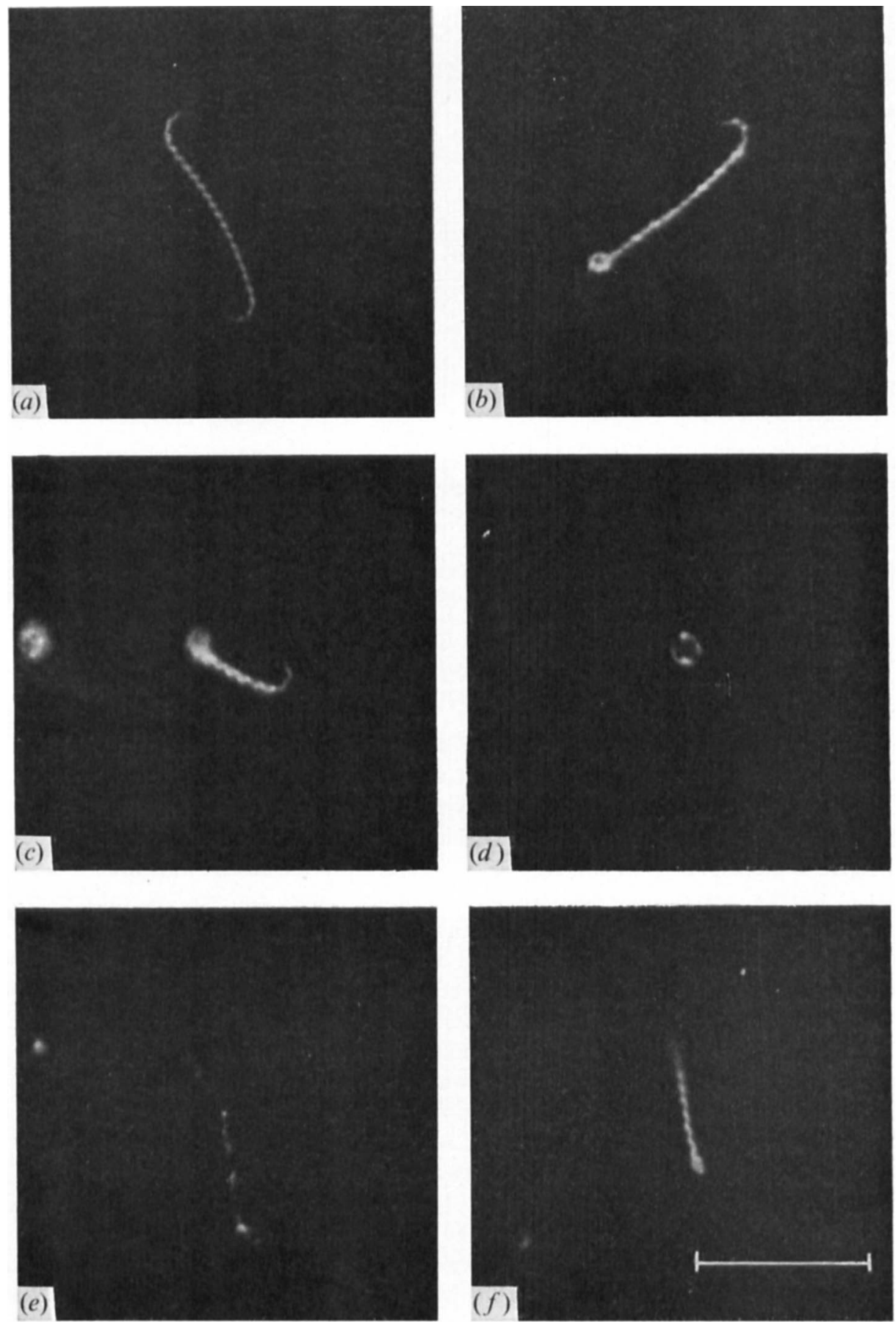

Fig. I. Leptospira interrogans. (a) 'Normal' leptospiral appearance in CAPS buffer, pH 9.6. (b) Small bleb at one end of the cell after $\mathrm{I} 5 \mathrm{~min}$ in CAPS buffer, $\mathrm{pH}$ 10.0. (c) Large bleb at one end of the cell after $30 \mathrm{~min}$ at $\mathrm{pH}$ 10.0: a spherule form is adjacent to the bleb form. (d) Spherule form, after 60 min exposure at $\mathrm{pH}$ 10.0. (e) Appearance in CAPS buffer, $\mathrm{pH}$ i I 0 . ( $f$ ) Appearance after $5 \mathrm{~min}$ in $0.5 \mathrm{M}$-sucrose and subsequent resuspension in $\mathrm{SM}_{4}$ medium. Bar marker represents $10 \mu \mathrm{m}$. 


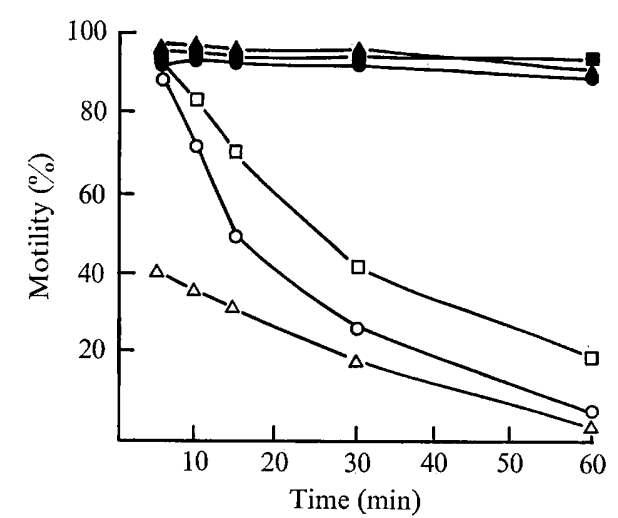

Fig. 2

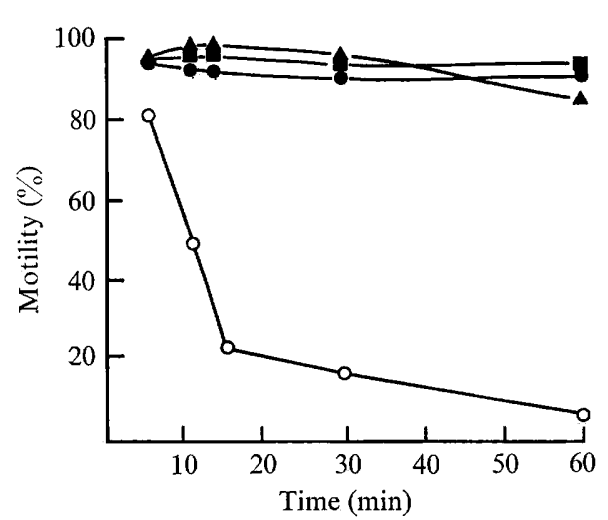

Fig. 3

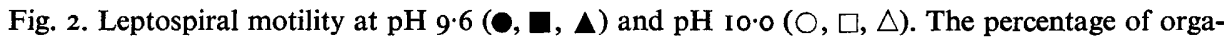
nisms counted showing motion of any kind is plotted against exposure time in the alkaline test solution. pH values were adjusted using I $\mathrm{M}$ solutions of $\mathrm{NaOH}(\mathrm{O}, \bullet), \mathrm{KOH}(\square, \square)$ or $\mathrm{NH}_{4} \mathrm{OH}$ $(\triangle, \Delta)$.

Fig. 3. The effect of $5 \times 10^{-3} \mathrm{M}$-EDTA on leptospiral motion at $\mathrm{pH} 7 \cdot 3$ and $\mathrm{pH} 9 \cdot 6$. The percentage of organisms counted showing motion of any kind is plotted against exposure time in the alkaline test solution. $\mathrm{pH}$ values were adjusted using I $\mathrm{M}-\mathrm{NaOH}$. $\mathbf{\square}, \mathrm{pH} 7 \cdot 3$, no EDTA;, $\mathrm{pH} 9 \cdot 6$, no EDTA; $\boldsymbol{\Delta}, \mathrm{pH} 7 \cdot 3$, EDTA present; $O$, $\mathrm{pH}_{9 \cdot 6}$, EDTA present.

\section{Effect of hypertonicity on leptospiral motion}

Suspension in either $0.5 \mathrm{M}$ or $\mathrm{I} \cdot \mathrm{O} \mathrm{M}$-sucrose completely inhibited leptospiral motion. Spontaneous recovery of movement was not observed even after $4 \mathrm{~h}$. Furthermore, when inoculated into $\mathrm{SM}_{4}$ medium supplemented with either $0.5 \mathrm{M}$ or $\mathrm{I} \cdot \mathrm{O} \mathrm{M}$-sucrose, $L$. interrogans did not grow. After $72 \mathrm{~h}$, microscopic examination showed only cell debris.

When the organism was suspended in $0.5 \mathrm{M}$-sucrose for various periods of time and subsequently washed and resuspended in SM4 medium, some recovery of movement was observed, although it was never complete (Table 2). The average percentage of leptospires recovering dropped significantly as the time of exposure to sucrose increased. Following short exposure periods (5 or $15 \mathrm{~min}$ ), recovery increased with time after resuspension in SM4 medium; but after longer periods of exposure to sucrose ( 30 or $60 \mathrm{~min}$ ), the length of time spent in the recovery medium had no influence. Fewer leptospires were able to regain motility if $\mathrm{I} \cdot \mathrm{OM}$ instead of $0.5 \mathrm{M}$-sucrose was used as the plasmolysing agent. Similar results were observed if $\mathrm{SM}_{4}$ medium was substituted for MOPS buffer or if MOPS buffer was used as a recovery medium in place of SM4. This indicates that metabolites do not cause the motility inhibition or the subsequent reversals.

When suspended in $0.5 \mathrm{M}$-sucrose, most organisms showed no structural alteration, although a few were seen to have small blebs at one end. On removal of the sucrose, and subsequent resuspension in $\mathrm{SM}_{4}$ medium, however, many of the organisms which regained their motility were observed to have small blebs at one end of the cell, giving them a 'spermlike' appearance (Fig. If). Even after $4 \mathrm{~h}$ such cells were still motile and occasionally exhibited translational movement. This indicates that leptospires were capable of motion even with some structural damage to the cell envelope.

Although it has been reported that ${ }^{2} \mathrm{H}_{2} \mathrm{O}$ acts as a mild plasmolytic agent for many flagellated bacteria (Zipf \& Doetsch, 1973), when $L$. interrogans was removed from its 
Table 2. Reversal of plasmolysis-induced inhibition of leptospiral motility

Leptospires were exposed to $0.5 \mathrm{M}$-sucrose for different times, and then the sucrose was removed, and the organisms were washed and resuspended in $\mathrm{SM}_{4}$ medium. Recovery is expressed as the percentage of total cells counted showing resumption of motion. Each test was performed in triplicate and the range of results is given in parenthesis.

Exposure to sucrose (min)

5

I5

30

60
Motility (\%)

0

○

0

0
Time in $\mathrm{SM}_{4}$ medium (min)

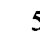

5

I 5

30

60

90

120

5

10

I 5

30

60

90

120

5

10

I5

30

60

90

I 20

5

10

I 5

30

60

90

120
Average recovery $(\%)$

$$
\begin{array}{cl}
55 & (44-64) \\
55 & (45-63) \\
58 & (54-62) \\
67 & (59-77) \\
67 & (54-79) \\
67 & (56-75) \\
70 & (60-75) \\
36 & (27-45) \\
32 & (29-36) \\
40 & (39-4 I) \\
50 & (45-53) \\
47 & (46-50) \\
5 I & (49-52) \\
50 & (49-5 I) \\
21 & (20-23) \\
21 & (17-24) \\
24 & (18-28) \\
24 & (20-28) \\
22 & (16-26) \\
21 & (15-24) \\
20 & (16-23) \\
3 & (I-6) \\
4 & (2-10) \\
4 & (I-8) \\
4 & (0-8) \\
3 & (0-7) \\
3 & (0-6) \\
3 & (0-7)
\end{array}
$$

growth medium, washed, and resuspended in $99 \cdot 8 \%{ }^{2} \mathrm{H}_{2} \mathrm{O}$, over $95 \%$ of the leptospires remained motile.

\section{DISCUSSION}

Schuetze \& Doetsch (1967) reported that various flagellated Gram-negative bacteria were immobilized at $\mathrm{pH}$ values of $9 \cdot 4$ to $10 \cdot 0$; for example, Escherichia coli was immobilized at $\mathrm{pH} 9 \cdot 4$, while Pseudomonas fluorescens was extremely active at $\mathrm{pH} 9 \cdot 4$, but non-motile at $\mathrm{pH}$ 10.0. On the other hand, Serratia marcescens was actively motile at $\mathrm{pH} 9 \cdot 8$. 'Paralysis' could readily be reversed by lowering the $\mathrm{pH}$ with acid; the movement of $E$. coli was stopped and started five times in 30 min simply by raising and lowering the $\mathrm{pH}$. It was suggested that the $\mathrm{pH}$-induced paralysis of eubacteria is an effect on the 'activating system' of their flagella rather than on the flagella themselves.

Leptospira interrogans tolerated relatively high concentrations of hydroxide ions. Motility similar to that in controls was consistently observed at $\mathrm{pH} 9 \cdot 6$ and continued at $\mathrm{pH}$ levels as high as $9 \cdot 8$. At $\mathrm{pH}$ i0.0, however, motility declined sharply as the time of exposure to the hydroxide ions increased. Structural alteration was observed concurrently with cessation of motility. Since similar effects were observed when either $\mathrm{NaOH}, \mathrm{KOH}$ or 
$\mathrm{NH}_{4} \mathrm{OH}$ was used to adjust the $\mathrm{pH}$, results can be attributed to the hydroxide ions and not the $\mathrm{Na}^{+}, \mathrm{K}^{+}$or $\mathrm{NH}_{4}{ }^{+}$ions. Once most of the leptospires either stopped moving or showed a blebbing of the envelope, these processes could not be reversed by lowering the $\mathrm{pH}$. Thus, hydroxide ion-induced inhibition of leptospiral motion appears to be permanent, in contrast to the reversible immobilization seen in flagellated eubacteria.

This contrast in behaviour is probably due to different mechanisms of propulsion. The eubacteria propel themselves by exoflagella, and alkali-induced paralysis appears to arise from some reversible effect of the hydroxide ions on the flagella-activating system. Leptospires, on the other hand, possess endoflagella which probably serve as their organelles of locomotion (Birch-Andersen, Hovind Hougen \& Borg-Petersen, I973; Nauman, Holt \& Cox, 1969). Hydroxide ion-induced immobilization is permanent and appears to be due, at least in part, to structural alterations in the cell envelope.

Evidence from the EDTA experiments implies that by restricting the entry of hydroxide ions, the cell envelope of $L$. interrogans protects its motility apparatus from any adverse effects. However, once the chemical structure or permeability of the cell envelope is altered, as with EDTA, pH levels which normally have no effect on motility can cause immobilization. In addition, structural alterations (such as bleb and spherule formation), normally seen only at high levels of $\mathrm{pH}$, occur at lower $\mathrm{pH}$ values. We suggest, therefore, that the leptospiral cell envelope acts as a semipermeable membrane that prevents the entry of hydroxide ions; but that at a certain concentration ( $\mathrm{pH} 10 \cdot 0)$, the hydroxide ions themselves begin to cause either an alteration in the permeability of the cell envelope or a modification of its relationship with the protoplasmic cylinder.

Auran et al. (1972) reported that, following exposure to $\mathrm{I} \cdot 0 \mathrm{M}-\mathrm{NaCl}$, the envelope of Leptospira serotype canicola formed small blebs at one end of the organism. This process then continued along the length of the organism until it became spherical. The protoplasmic cylinder was observed folded back upon itself within the bounding membrane. Since identical forms (small blebs, large blebs and spherules) were observed with $L$. interrogans at $\mathrm{pH}$ values of 10.0 to 10.6, it is likely that similar events to those reported by Auran and co-workers occurred here. A plausible explanation for alkali-induced spherule formation and concomitant loss of motion assumes that there is, under normal conditions, an association between the wall of the protoplasmic cylinder and the cell envelope. High concentrations of hydroxide ions modify this association either by altering cell envelope permeability, thus allowing an influx of hydroxide ions, or by causing dissociation of the envelope from the protoplasmic cylinder. As a result, the loosened membrane assumes a spherical form of lowest free energy and forms what might be termed a 'pseudoprotoplast'. During spherulation, motion ceases, either as a direct result of the structural displacement of the envelope or as a consequence of ion-induced inhibition of metabolic reactions associated with motility. Since the endoflagella lie wrapped around the protoplasmic cylinder in the area between the wall and the cell envelope, any displacement of the envelope from the protoplasmic cylinder might prevent their normal functioning. It is equally possible that the hydroxide ions, at high enough concentrations, alter the permeability of the envelope and inhibit motility-associated metabolic reactions independently of the spherulation process.

A second environmental factor shown to affect the motility of leptospires is hypertonicity. Leptospira interrogans was completely immobilized in $0.5 \mathrm{M}$ and $\mathrm{I} \cdot 0 \mathrm{M}$ solutions of sucrose. Unlike eubacteria.which, on plasmolysis with sucrose, revert to motile forms both spontaneously and when deplasmolysed (Okrend \& Doetsch, 1969), leptospires showed no spontaneous reversal of hypertonicity-induced motility inhibition. In fact, the degree of 
reversal following exposure varied with both the concentration and the time of exposure to the sucrose.

Okrend \& Doetsch (1969) suggested that during plasmolysis displacement of the cytoplasmic membrane disrupted flagellar function in eubacteria. This could not be confirmed microscopically, however, with $L$. interrogans because of their narrowness $(0 \cdot \mathrm{I} \mu \mathrm{m})$ and their resistance to staining. Electron microscopy was not attempted because of difficulties normally encountered in resolving the cytoplasmic membrane and cell wall of leptospires and because of the uncertainty of proving that membrane displacement, if observed, occurred as a direct result of the sucrose and not the fixation and dehydration procedures. Evidence indicated that inhibition of motility may have had some biochemical basis (possibly from dehydration effects) since there was no multiplication and the organisms lysed upon incubation in $\mathrm{SM}_{4}$ medium supplemented with $0.5 \mathrm{M}$ or $\mathrm{I} \cdot 0 \mathrm{M}$ sucrose. The manner in which hypertonicity causes the detrimental effects is at present unknown.

Although leptospires possess endoflagella which are morphologically and chemically analogous to the exoflagella of eubacteria, their behaviour in response to various environmental factors differs. These behavioural differences are due, most likely, to the unique morphology of leptospires.

\section{REFERENCES}

Auran, N. E., Johnson, R. C. \& RitzI, D. M. (1972). Isolation of the outer sheath of Leptospira and its immunogenic properties in hamsters. Infection and Immunity 5, 968-975.

Birch-Andersen, A., Hovind Hougen, K. \& Borg-Petersen, C. (1973). Electron microscopy of Leptospira. I. Leptospira strain pomona. Acta pathologica et microbiologica scandinavica B 81, 665-676.

HenneberRy, R. C., Baseman, J. B. \& Cox, C. D. (1970). Growth of a water strain of Leptospira on synthetic media. Antonie van Leeuwenhoek 36, 489-501.

INDGE, K. J. (1968). The effects of various anions and cations on the lysis of yeast protoplasts by osmotic shock. Journal of General Microbiology 51, 425-432.

KAISER, G. E. \& DoETSCH, R. N. (I975). Enhanced translational motion of Leptospira in viscous environments. Nature, London 255, 656-657.

Kiktenko, V. S., Bakulina, N. A. \& Levina, L. F. (1974). Concerning the granule formation in leptospirae. Byulleten' Éksperimental'noi biologii $i$ meditsiny 76, 83-86.

Nauman, R. K., Holt, S. C. \& Cox, C. D. (1969). Purification, ultrastructure and composition of axial filaments from Leptospira. Journal of Bacteriology 98, 264-280.

Okrend, A. G. \& DoetsCh, R. N. (I969). Plasmolysis and bacterial motility: a method for the study of membrane function. Archiv für Mikrobiologie 69, 69-78.

SCHNEIDER, W. R. \& DOETSCH, R. N. (1974). Effect of viscosity on bacterial motility. Journal of Bacteriology II7, 696-70I.

SChuetze, P. L. \& Doetsch, R. N. (1967). Reversible 'paralysis' of the flagella of certain Gram-negative bacteria. Canadian Journal of Microbiology 13 , 1 I I 4-I I I 5.

ZIPF, M. E. \& DoETSCH, R. N. (1973). Effects of deuterium oxide on bacterial flagellar motility. Archiv für Mikrobiologie 92, $32 \mathrm{I}-330$. 